\title{
How Does Chitosan Affect Methane Production in Anaerobic Digestion?
}

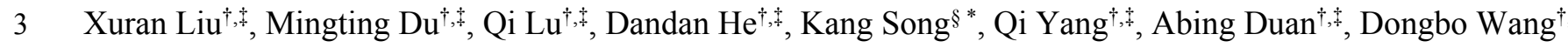

¥Key Laboratory of Environmental Biology and Pollution Control (Hunan University), Ministry of Education,

${ }^{\S}$ State Key Laboratory of Freshwater Ecology and Biotechnology, Institute of Hydrobiology, Chinese Academy of Sciences, Wuhan 430072, P.R. China

17 The Number of Pages: 13

18 The Number of Tables: 6

19 The Number of Figures: 6 
Modified Gompertz Model Analysis. Methane production was simulated by the modified Gompertz equation (Eq 1), and kinetic parameters ( $M m$, maximum methane yield potential, $\mathrm{mL} / \mathrm{g} \mathrm{VS} ; \mathrm{Rm}$, maximum methane production rate, $\mathrm{mL} /(\mathrm{g} \mathrm{VS} \cdot \mathrm{d}) ; \lambda$, lag-phase time of methane production, $\mathrm{d}$; and t, digestion time, $\mathrm{d} ; e$ is $\exp (1)$.) were calculated using Origin 7.0 software.

$$
\mathrm{M}=M m \times \exp \left\{-\exp \left[\frac{R m \times e}{M m}(\lambda-\mathrm{t})+1\right]\right\}
$$

The relationships of chitosan concentration with maximum methane yield potential $(\mathrm{Mm}, \mathrm{mL} / \mathrm{g}$ VS or $\mathrm{mL} / \mathrm{L})$, methane production rate $(R m, \mathrm{~mL} /(\mathrm{g} \mathrm{VS} \cdot \mathrm{d})$ or $\mathrm{mL} /(\mathrm{L} \cdot \mathrm{d}))$ and lag phase time of methane production $(\lambda, d)$ can be simulated by exponential equations using Origin 7.0 software.

Effects of Chitosan on the Individual Steps Involved in Anaerobic Digestion. Test-I, Test- II, Test-III, and Test-IV were respectively used to evaluate the impact of chitosan on hydrolysis, acidogenesis, acetate-dependent methanogenesis, and $\mathrm{CO}_{2}$-dependent methanogenesis. All these tests were lasted for $3 \mathrm{~d}$.

Test-I: The three reactors received $920 \mathrm{~mL}$ synthetic wastewater and $80 \mathrm{~mL}$ of purified inoculum withdrawn from the reactors at the times when the methane production no longer increased in the "Effects of Chitosan on Anaerobic Digestion of Sludge during Batch Experiments". The synthetic wastewater contains $6.0 \mathrm{~g}$ BSA and $1.2 \mathrm{~g}$ dextran. Two reactors were respectively fed with 0.085 and $0.339 \mathrm{~g}$ chitosan (the amount of chitosan is equally to that in the 4 and $16 \mathrm{~g} / \mathrm{kg}$ TSS chitosan reactors, respectively) while the other reactor received no chitosan and was set as the control. All other conditions were the same as those described in batch experiments. By measuring the degradation rates of BSA and dextran, the effect of chitosan on hydrolysis process could be indicated.

Test-II: This test was operated the same as described in Test-I except that the substrates (i.e., BSA and dextran) in synthetic wastewater were replaced by $4.0 \mathrm{~g}$ L-alanine and $0.8 \mathrm{~g}$ glucose, respectively. 
Test-III: This test was operated the same as described in Test-I except that the substrates (i.e., BSA and dextran) in synthetic wastewater were replaced by 3.0 g sodium acetate.

Test-IV: The operation of this test was performed with the same approach as described in Test-I except that the substrates (i.e., BSA and dextran) in synthetic wastewater were replaced by the mixture of standard gas (40\% hydrogen, $10 \%$ carbon dioxide and $50 \%$ nitrogen).

Inoculum Purification. The inoculum was firstly withdrawn from the reactors of the control and the reactor with corresponding chitosan levels dosed at the times when the methane production no longer increased in the "Effects of Chitosan on Anaerobic Digestion of Sludge during Batch Experiments", respectively. And then rinsed with sterilized saline solution $(0.9 \% \mathrm{NaCl} ; \mathrm{w} / \mathrm{v})$ and stirred evenly, and re-suspended in $250 \mathrm{~mL}$ sterilized $0.9 \% \mathrm{NaCl}$, and were further preserved at $4{ }^{\circ} \mathrm{C}$ for further use.

Synthetic Wastewater for Investigating the Chitosan Anaerobic Biodegradation. The synthetic wastewater contained buffering chemicals and a sufficient amount of inorganic nutrients without carbon source addition are as follows (mg/L): $\mathrm{NH}_{4} \mathrm{Cl} 400 ; \mathrm{K}_{2} \mathrm{HPO}_{4} \cdot 3 \mathrm{H}_{2} \mathrm{O} 155 ; \mathrm{CaCl}_{2} 50 ; \mathrm{MgCl}_{2} \cdot 6 \mathrm{H} 2 \mathrm{O} 100 ; \mathrm{FeCl}_{2}$ 25; $\mathrm{NaCl} 10 ; \mathrm{CoCl}_{2} \cdot 6 \mathrm{H}_{2} \mathrm{O} 5 ; \mathrm{MnCl}_{2} \cdot 4 \mathrm{H}_{2} \mathrm{O} 5 ; \mathrm{AlCl}_{3}$ 2.5; $\left(\mathrm{NH}_{4}\right)_{6} \mathrm{Mo}_{7} \mathrm{O}_{24} \quad 15 ; \mathrm{H}_{3} \mathrm{BO}_{3} \quad$ 5; $\mathrm{NiCl}_{2} \cdot 6 \mathrm{H}_{2} \mathrm{O} \quad$; $\mathrm{CuCl}_{2} \cdot 5 \mathrm{H}_{2} \mathrm{O} 5 ; \mathrm{ZnCl}_{2} 5$.

\section{Protease and a-glucosidase Activity Measurement, Illumina Miseq Sequencing and Real-time}

Quantitative PCR Procedures. For protease and $\alpha$-glucosidase activity measurement, digestion mixtures were harvested and washed for 3 times with $50 \mathrm{mM}$ Tris- $\mathrm{HCl}$ (pH 7.5) containing $2 \mathrm{mM}$ dithiothretol and 1 $\mathrm{mM}$ phenylmethylsulfonyl fluoride. Then, the resuspended cells were sonicated at $20 \mathrm{kHz}$ for $45 \mathrm{~min}$ in an ice bath to break down the cell structure. The debris was centrifuged at $12000 \mathrm{~g}$ and $4{ }^{\circ} \mathrm{C}$ for $30 \mathrm{~min}$, and the crude extracts in supernatant were obtained for protease and $\alpha$-glucosidase activity measurement. The relative activity of protease was measured by the published methods. ${ }^{2}$ The $\alpha$-glucosidase activity was 
analyzed using the method of Luo et al with potassium acetate as the substrate. ${ }^{2}$ For illumina Miseq sequencing and real-time quantitative PCR, $10 \mathrm{~mL}$ of sludge was taken from each reactor and harvested via centrifugation $(11000 \mathrm{~g})$ at $4{ }^{\circ} \mathrm{C}$ for $20 \mathrm{~min}$. Genomic DNA was extracted using an extraction kit (Major Biotech, Shanghai, China). The V3-V4 region of the archaeal and bacterial 16S rRNA genes was amplified using the universal primers $349 \mathrm{~F}$ (50-GYGCASCAGKCGMGAAW-30)/806R (50-GGACTACVSGGGTATCTAAT-30) and the universal primers $341 \mathrm{~F}$ (50-CCTACGGGNGGCWGCAG-30)/805R

After being purified and quantified, pyrosequencing was carried out using Illumina high-throughput sequencing on the MiSeq platform (Major Biotech, Shanghai, China). In real-time PCR assays, the primers, PCR reactions mixtures and procedures were shown below (Table S1, S2 and S3). All PCR assays were performed using three replicates per sample and contained the control reactions without template DNA. The copy number of total genes was calculated using a standard curve generated by using 10 -fold serial dilutions of linearized plasmids containing the gene fragment as a template.

Other Analytical Methods. The methane fraction in biogas was analyzed by gas chromatograph (GC112A, China) equipped with a thermal conductivity detector according to the method documented in the literature. ${ }^{3,4}$ The flocs size distribution analysis was performed using a Malvern Mastersizer 2000 instrument with a detection range of $0.01 \sim 3500 \mu \mathrm{m}$. EPS was extracted using a modified heat extraction method, and their major functional groups were determined by Fourier transform infrared spectroscopy (NICOLET 8700, Thermo Fisher Scientific, USA). ${ }^{5}$ The excitation emission matrix (EEM) fluorescence spectroscopy (F-4600, Hitachi, Japan) was applied to characterize the changes of EPS according to the method reported previously. ${ }^{6} \quad$ The chitosan and its potential metabolites were extracted by repeatedly acidic-water washing, and their qualification were performed by high performance liquid chromatography method documented in the 
87 literature. ${ }^{7,8}$ The molecular weights (MW) distribution of chitosan was determined by a Gel Permeation 88 Chromatography (PL-GPC 220), which was equipped with a differential detector (RID-10A). The GPC was 89 run with the aqueous buffer $(0.15 \mathrm{M}$ ammonium acetate $/ 0.2 \mathrm{M}$ acetic acid, $0.02 \%$ sodium azide, $\mathrm{pH} 4.5)$ at a 90 flow rate of $0.8 \mathrm{~mL} / \mathrm{min}^{9}$

91 
Table S1. The main characteristics of sludge and inoculum used in this study

\begin{tabular}{cccc}
\hline Parameters & Unit & WAS $^{\text {a }}$ & Inoculum \\
\hline pH & & $6.8 \pm 0.1$ & $7.4 \pm 0.1$ \\
TS (total solids) & $\mathrm{g} / \mathrm{L}$ & $26480 \pm 600$ & $18500 \pm 550$ \\
VS (volatile solids) & $\mathrm{g} / \mathrm{L}$ & $18200 \pm 350$ & $13200 \pm 260$ \\
TCOD (total chemical oxygen demand) & $\mathrm{g} / \mathrm{L}$ & $26500 \pm 400$ & $21700 \pm 420$ \\
$\mathrm{SCOD}$ (soluble chemical oxygen demand) & $\mathrm{g} / \mathrm{L}$ & $480 \pm 30$ & - \\
Total protein & $\mathrm{g} \mathrm{COD} / \mathrm{L}$ & $13120 \pm 100$ & - \\
Total carbohydrate & $\mathrm{g} \mathrm{COD} / \mathrm{L}$ & $2740 \pm 120$ & - \\
$\mathrm{NH}_{4}{ }^{+}-\mathrm{N}$ (ammonium nitrogen) & $\mathrm{mg} / \mathrm{L}$ & $34.8 \pm 3.0$ & - \\
\hline
\end{tabular}

${ }^{\text {a }}$ Data are shown as arithmetic mean of three replicates \pm standard deviation.

Table S2. Primer sequences and annealing temperatures of PCR and qPCR assays

\begin{tabular}{|c|c|c|c|}
\hline Target Gene & Primer/Probe sequence & Annealing Temperature & Reference \\
\hline$A K$ & $\begin{array}{c}\text { F: CTCAGATGCTGGGCAAACCT } \\
\text { R: ACAAATACTTGCTCCGTTTCCAA }\end{array}$ & $60^{\circ} \mathrm{C}$ & 2 \\
\hline FTHFS & $\begin{array}{l}\text { F: TTYACWGGHGAYTTCCATGC } \\
\text { R: GTATTGDGTYTTRGCCATACA }\end{array}$ & $53^{\circ} \mathrm{C}$ & 10 \\
\hline$A C A S$ & $\begin{array}{l}\text { F: TAATCCGCCAAAAGAGTTGG } \\
\text { R: TCTTCTGGACTGGCTGGTCT }\end{array}$ & $56^{\circ} \mathrm{C}$ & 11 \\
\hline$m c r A$ & $\begin{array}{c}\text { F: TTCGGTGGATCDCARAGRGC } \\
\text { R: GBARGTCGWAWCCGTAGAATCC }\end{array}$ & $58^{\circ} \mathrm{C}$ & 12 \\
\hline
\end{tabular}

Table S3. PCR reaction mixture

\begin{tabular}{ccc}
\hline Reaction component & Concentration & Volume $(\mu \mathrm{L})$ \\
\hline SybrGreen qPCR Master Mix & $2 \mathrm{X}$ & 12.5 \\
Primer F & $10 \mu \mathrm{M}$ & 0.5 \\
Primer R & $10 \mu \mathrm{M}$ & 0.5 \\
Deionized Water & & 9.5 \\
Template (cDNA) & & 2 \\
Total & & 25 \\
\hline
\end{tabular}

Table S4. PCR reaction conditions

Time and Temperature

Thermal cycle
Each of 40 cycles

Melt




\begin{tabular}{cccc}
\hline & Hold & Cycle & 12.5 \\
Real-Time Quantitative & $15 \mathrm{~min}$ & $10 \mathrm{sec}$ & $1 \mathrm{~min}$ \\
PCR (ABI 7500) & $95^{\circ} \mathrm{C}$ & $95^{\circ} \mathrm{C}$ & Annealing Temperature $^{\text {a }}$ \\
\hline
\end{tabular}

100 a The value was selected based on the target gene listed in Table S2.

101

102 Table S5. Statistical analysis results of the maximal cumulative methane production between the 103 control and $4 \mathrm{~g}$ chitosan/ $\mathrm{kg}$ TSS added digester

\begin{tabular}{cccc}
\hline \multirow{2}{*}{ Treatment } & \multicolumn{3}{c}{ Statistical analysis value } \\
\cline { 2 - 4 } & $\mathrm{F}$ & $\mathrm{F}$ crit & P-value \\
\hline $4 \mathrm{~g} / \mathrm{kg}$ TSS vs Control & 3.8875 & 7.7086 & 0.07647 \\
\hline
\end{tabular}

104

Table S6. Estimated Hm, Rm, and $\lambda$ at different chitosan levels using Gompertz equationa

\begin{tabular}{clccc}
\hline Chitosan dosages & \multicolumn{4}{c}{ Kinetic model parameters } \\
\cline { 2 - 5 }$(\mathrm{g} / \mathrm{kg} \mathrm{TS})$ & $H m(\mathrm{~mL} / \mathrm{g} \mathrm{VS})$ & $R m(\mathrm{~mL} /(\mathrm{g} \mathrm{VS} \cdot \mathrm{d}))$ & $\lambda(\mathrm{d})$ & $\mathrm{R}^{2}$ \\
\hline 0 & $165.5 \pm 4.4$ & $14.4 \pm 0.2$ & $3.25 \pm 0.10$ & 0.985 \\
4 & $169.3 \pm 4.7$ & $13.5 \pm 0.3$ & $4.15 \pm 0.16$ & 0.992 \\
8 & $153.7 \pm 5.3$ & $10.1 \pm 0.2$ & $4.51 \pm 0.14$ & 0.977 \\
16 & $145.8 \pm 4.6$ & $8.3 \pm 0.3$ & $6.02 \pm 0.25$ & 0.987 \\
32 & $130.1 \pm 5.5$ & $5.9 \pm 0.3$ & $7.57 \pm 0.40$ & 0.982 \\
\hline
\end{tabular}

${ }^{\text {a }}$ The results are average of triplicate tests. 

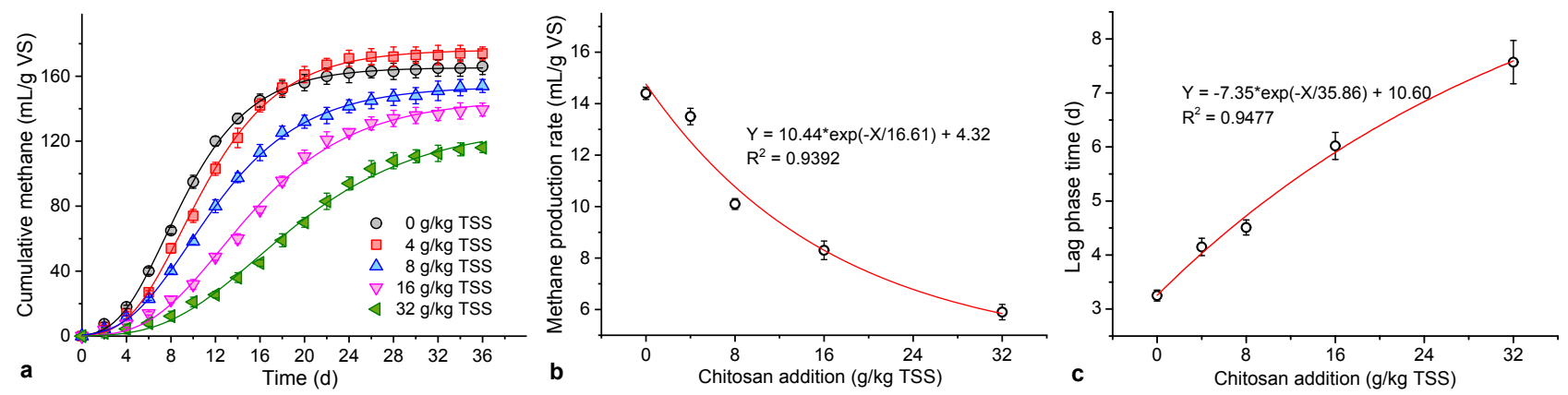

108 Figure S1. Cumulative methane production during sludge anaerobic digestion in the presence of different 109 levels of chitosan addition (a), and correlation between chitosan addition and maximum methane production 110 rate from model fit (b), and lag phase time from model fit (c). Symbols represent experimental 111 measurements and lines represent model fit. 


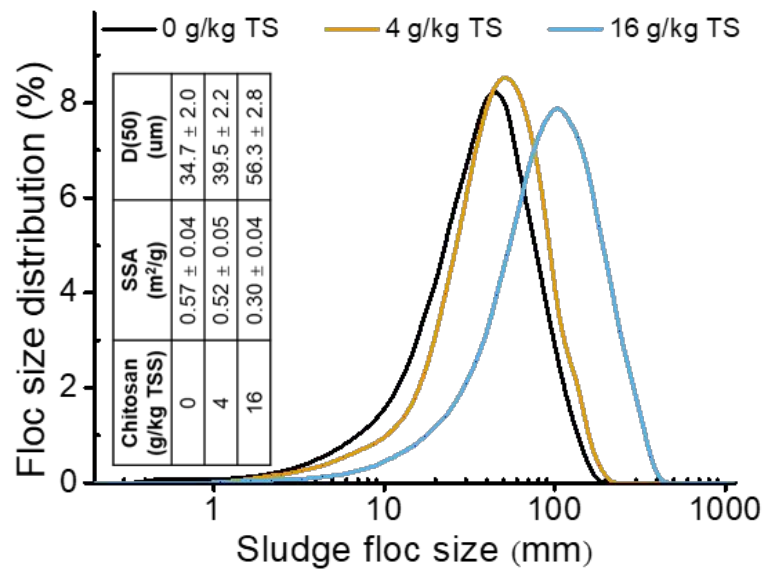

113

114 Figure S2. Effect of chitosan addition on the sludge particle size distribution. Data are mean \pm SD of three 115 independent experiments.

116 


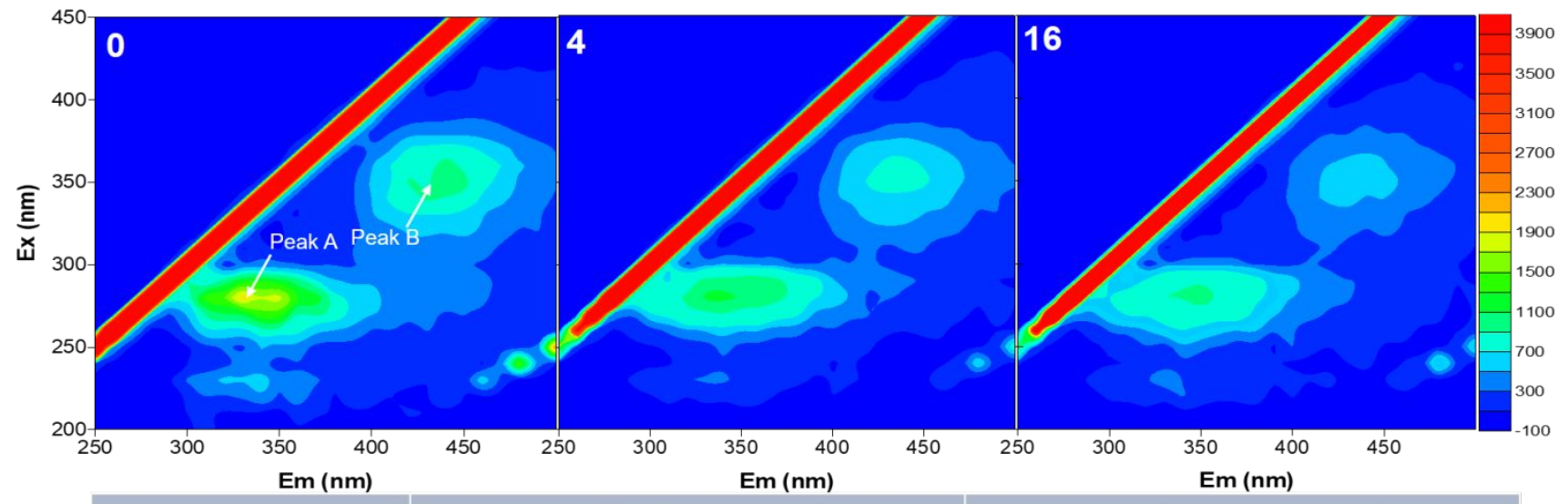

\begin{tabular}{|c|c|c|c|c|}
\hline \multirow{2}{*}{$\begin{array}{c}\text { Chitosan addition } \\
\text { (g/kg TSS) }\end{array}$} & \multicolumn{2}{|c|}{ Peak A (byproduct-like substances) } & \multicolumn{2}{c|}{ Peak B (humic-acid-like substances) } \\
\hline 0 & Ex/Em (nm) & Intensity (a.u.) & Ex/Em (nm) & Intensity (a.u.) \\
\hline $\mathbf{4}$ & $270 / 330$ & 2056 & $350 / 440$ & 1247 \\
\hline $\mathbf{1 6}$ & $270 / 335$ & 1370 & $350 / 445$ & 884 \\
\hline
\end{tabular}

118 Figure S3. EEM profiles of liquid supernatant on digestion day 8. The substances located in Peak A is 119 generally identified as byproduct-like substances, and in Peak B is generally identified as humic-acid-like 120 substances. 


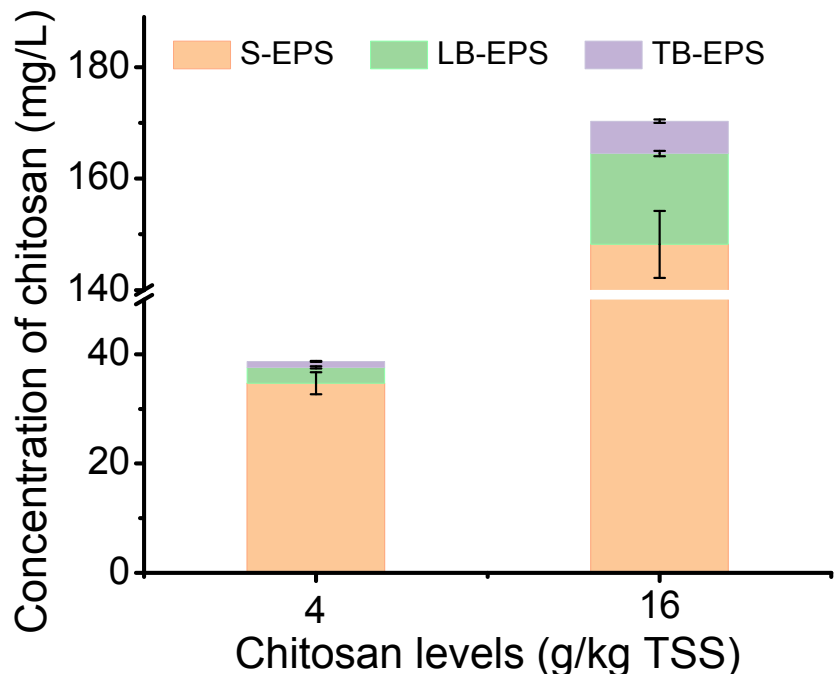

123 Figure S4. The concentration of chitosan in EPS of anaerobic microbes after 6 days of growth. Data are 124 mean \pm SD of three independent experiments. 

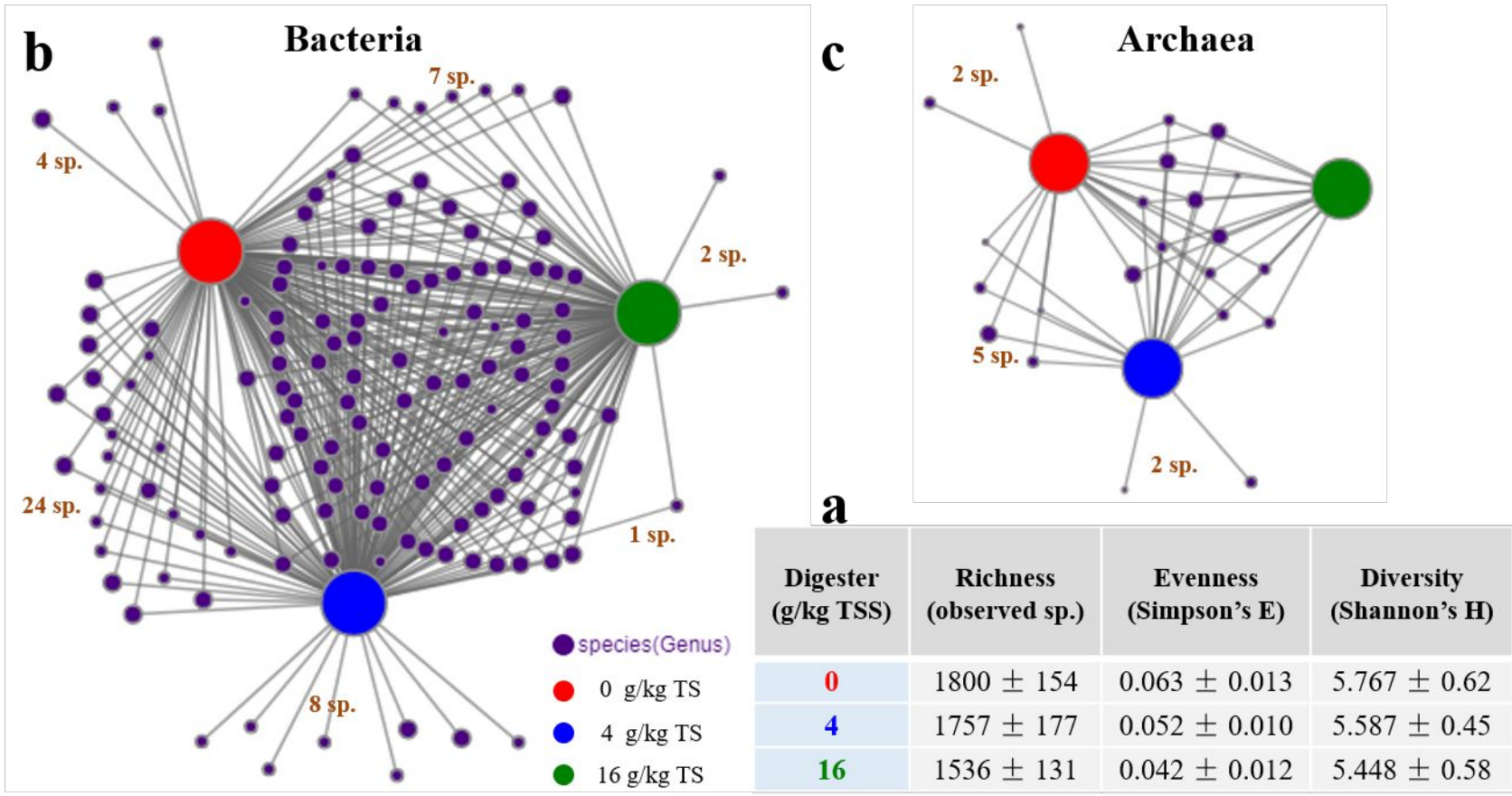

126 Figure S5. Microbial $\alpha$-Diversity metrics at different digesters (a), and bipartite association network showing the associations of bacteria (b) and archaea (c) in each digester at genus level. Node sizes represent relative abundance (square root) of the species (Genus) in the data sets. Edges represent the association patterns of individual species with the digesters. The edge-weighted spring-embedded algorithm pulled together species with similar associations and systems with similar structure. 

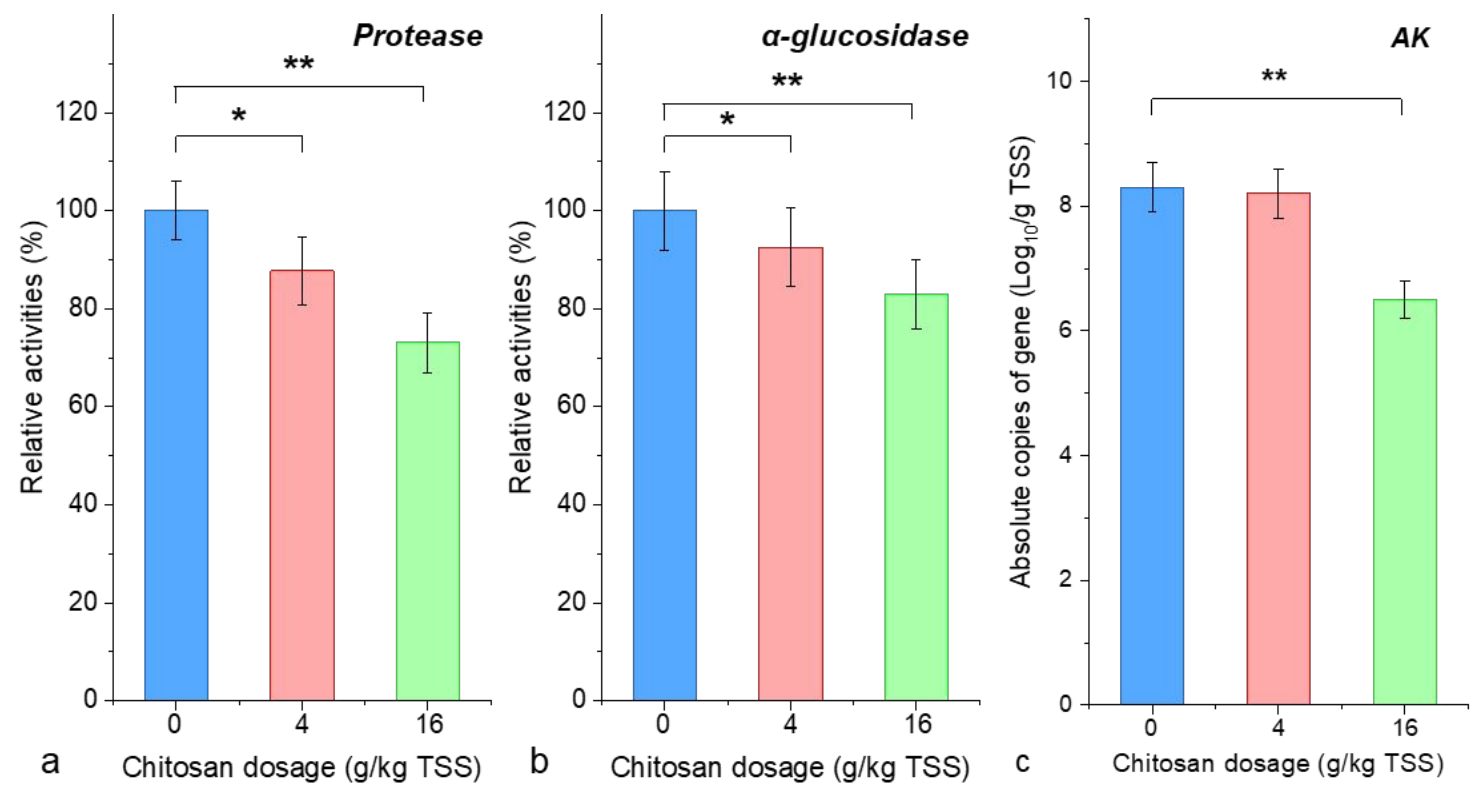

a Chitosan dosage (g/kg TSS)

b Chitosan dosage ( $\mathrm{g} / \mathrm{kg}$ TSS)
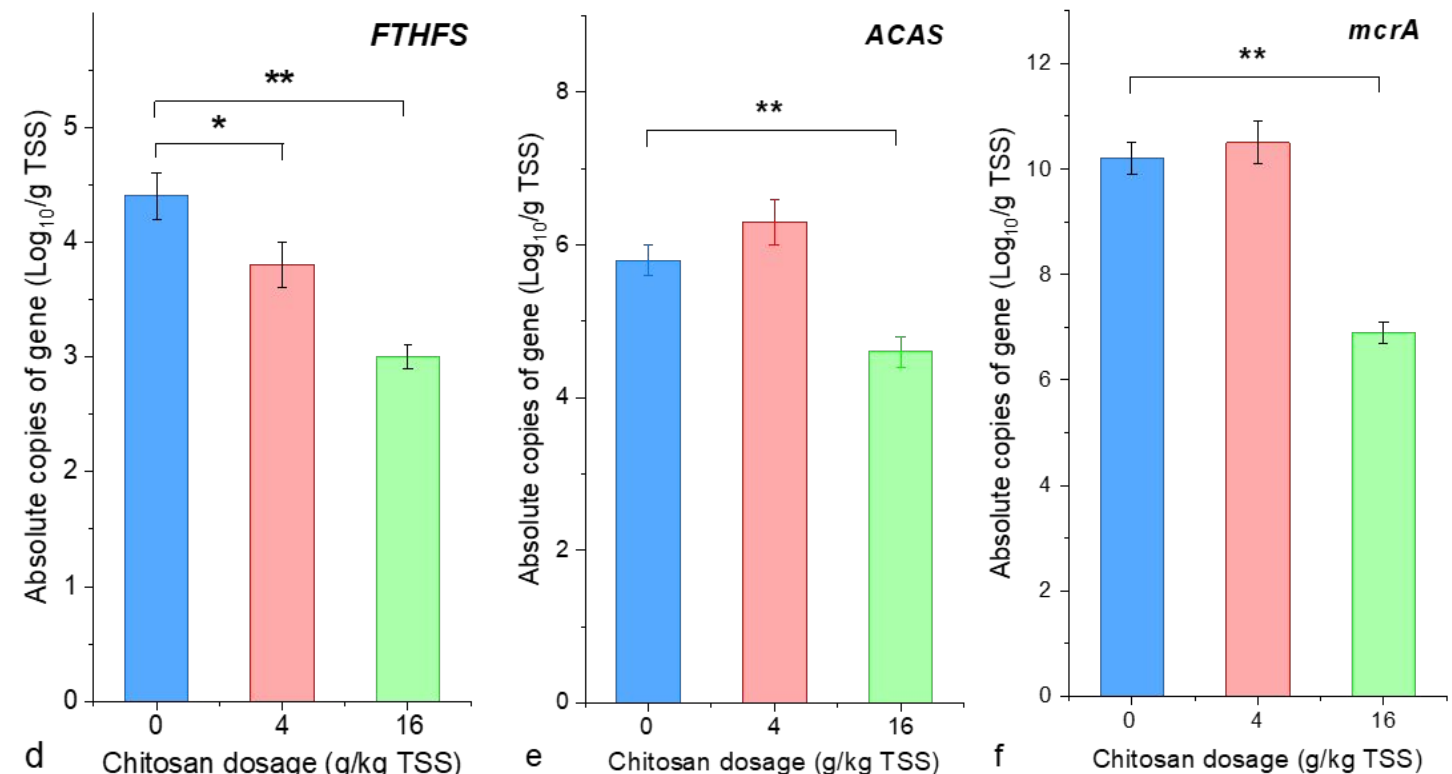

133 Figure S6. Effects of chitosan on the relative activities of protein (a), $\alpha$-glucosidase (b), and the quantities 134 of $A K(\mathrm{c}), F T H F S$ (d), ACAS (e), mcrA (f) genes in the long-term operated reactors. Data in a-f are mean \pm 135 SD of three independent experiments. 
137 (1) Ren, T.T.; Mu, Y.; Yu, H.Q.; Harada, H.; Li, Y.Y. Dispersion analysis of an acidogenic UASB reactor. 138 Chem. Eng. J. 2008. 142, 182-189.

139 (2) Luo, J.; Chen, Y.; Feng, L. Polycyclic Aromatic Hydrocarbon Affects Acetic Acid Production during 140 Anaerobic Fermentation of Waste Activated Sludge by Altering Activity and Viability of Acetogen. Environ. 141 Sci. Technol. 2016, 50, 6921-6929.

142 (3) Liu, H.; Chen, Y. Enhanced Methane Production from Food Waste Using Cysteine To Increase 143 Biotransformation of 1-Monosaccharide, Volatile Fatty Acids, and Biohydrogen. Environ. Sci. Technol. 2018, $144 \quad 52,3777-3785$.

145 (4) $\mathrm{Mu}, \mathrm{H}$;; Chen, Y. Long-term effect of $\mathrm{ZnO}$ nanoparticles on waste activated sludge anaerobic digestion. 146 Water Res. 2011, 45, 5612-5620.

147 (5) Wu, Y.; Liu, X.; Wang, D.; Chen, Y.; Yang, Q.; Chen, Y.; Hu, X.; Xu, Q.; Fu, Q.; Du, C. Iron electrodes 148 activating persulfate enhances acetic acid production from waste activated sludge. Chem. Eng. J. 2020, 390, 149124580.

150 (6) Mairinger, T.; Loos, M.; Hollender, J. Characterization of water-soluble synthetic polymeric substances 151 in wastewater using LC-HRMS/MS. Water Res. 2021, 190, 116745.

152 (7) Mohammadi, M.; Zamani, A.; Karimi, K. Determination of Glucosamine in Fungal Cell Walls by 153 High-Performance Liquid Chromatography (HPLC). J. Agric. Food Chem. 2012, 60, 10511-10515.

154 (8) Wu, T.; Zivanovic, S.; Hayes, D. G.; Weiss, J. Efficient reduction of chitosan molecular weight by 155 high-intensity ultrasound: underlying mechanism and effect of process parameters. J. Agric. Food. Chem. $156 \quad 2008,56,5112-5119$.

157 (9) Ratajska, M.; Strobin, G.; Wiśniewska-Wrona, M.; Ciechańska, D.; Fibres, W. B. J.; Europe, T. i. E. 158 Studies on the Biodegradation of Chitosan in an Aqueous Medium. J. Appl. Polym. 2003, 11, 75-79.

159 (10) Lovell, C. R.; Leaphart, A. B., Community - Level Analysis: Key Genes of $\mathrm{CO}_{2}$-Reductive Acetogenesis. 160 In Methods in Enzymology, Academic Press: 2005, 397, 454-469.

161 (11) Ince, B.; Koksel, G.; Cetecioglu, Z.; Oz, N. A.; Coban, H.; Ince, O. Inhibition effect of isopropanol on 162 acetyl-CoA synthetase expression level of acetoclastic methanogen, Methanosaeta concilii. J. Biotechnol. 163 2011, 156, 95-99.

164 (12) Wang, T.; Zhang, D.; Dai, L.; Dong, B.; Dai, X. Magnetite Triggering Enhanced Direct Interspecies 165 Electron Transfer: A Scavenger for the Blockage of Electron Transfer in Anaerobic Digestion of High-Solids 166 Sewage Sludge. Environ. Sci. Technol. 2018, 52, 7160-7169. 